\title{
Effect of dietary habits on the risk of metabolic syndrome: Yazd Healthy Heart Project
}

\author{
Mohammadtaghi Sarebanhassanabadi ${ }^{1}$, Seyed Jalil Mirhosseini ${ }^{1}$, Masoud Mirzaei ${ }^{1, *}$, \\ Seyedeh Mahdieh Namayandeh ${ }^{1}$, Mohammad Hossein Soltani ${ }^{1}$, Mohammadreza \\ Pakseresht $^{2}$, Ali Pedarzadeh ${ }^{1}$, Zahra Baramesipour ${ }^{1}$, Reza Faraji ${ }^{1}$ and \\ Amin Salehi-Abargovei $i^{3,4}$ \\ ${ }^{1}$ Yazd Cardiovascular Research Center, Shahid Sadoughi University of Medical Sciences, Afshar Hospital, Jomhouri \\ Blvd, Postal code: 8917945556, Yazd, Islamic Republic of Iran: ${ }^{2}$ Department of Agricultural, Food and Nutritional \\ Sciences, University of Alberta, Edmonton, Alberta, Canada: ${ }^{3}$ Nutrition and Food Security Research Center, Shahid \\ Sadoughi University of Medical Sciences, Yazd, Islamic Republic of Iran: ${ }^{4}$ Department of Nutrition, School of Public \\ Health, Shahid Sadoughi University of Medical Sciences, Yazd, Islamic Republic of Iran
}

Submitted 28 April 2017: Final revision received 22 October 2017: Accepted 3 November 2017: First published online 13 December 2017

\begin{abstract}
Objective: Metabolic syndrome (MetS) refers to a group of risk factors that increase the risk of cardiovascular mortality and morbidity. Dietary habits are among the most important risk factors for MetS. The current study aimed at assessing the effect of dietary habits on the risk of MetS in a 10-year follow-up study in central Iran.

Design: Cohort study.

Setting: Yazd, Iran.

Subjects: Participants aged 20-74 years without any history of MetS, who were originally recruited for Yazd Healthy Heart Project (YHHP) during 2005-2006, were revisited during 2015-2016. At phase I of YHHP, demographic data, anthropometric measurements, five components of MetS, biochemical tests and dietary habits were evaluated; and the same data were collected in phase II.

Results: A total of 1092 participants were eligible to be included in the present study. After follow-up, the 10-year cumulative incidence of MetS was 56.1\%. After adjustment for potential confounders, increased risk of MetS (hazard ratio; 95\% CI) was found in those who did not try to control their body weight $(1 \cdot 57 ; 1 \cdot 06,2 \cdot 35)$, did not usually eat salad $(1.91 ; 1.22,3.00)$ and added salt to their food $(1.57,1.06$, 2.33). These associations were stronger in men than in the total population after subgroup analysis, but were not present in women.

Conclusions: Dietary habits affect the risk of MetS in the Iranian population. Lifestyle interventions are needed to improve dietary habits to reduce the risk of MetS. Future studies are highly recommended to confirm our results in other populations.
\end{abstract}

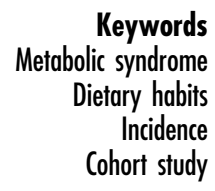

Metabolic syndrome (MetS) is a set of metabolic abnormalities, including abdominal obesity, high fasting blood glucose, hypertension, decreased HDL cholesterol (HDL-C) and high TAG level, which increases cardiovascular and non-cardiovascular mortality and morbidity risks ${ }^{(1)}$. The prevalence of MetS varies around the world. For example, in the National Health and Nutrition Examination Survey (NHANES) during 2003-2006, the prevalence of MetS according to the National Cholesterol Education Program's Adult Treatment Panel III (NCEP ATP III) criteria was 34\% in American people aged over 20 years $^{(2)}$. In central Iran, more than $32 \%$ of the population suffers from $\mathrm{MetS}^{(3)}$.
However, MetS is growing rapidly worldwide. For instance, MetS has increased in the adult population in China from 2005 (31.6\% in females and $26.3 \%$ in males) to 2014 $\left(48.3 \%\right.$ in females and $41.0 \%$ in males) ${ }^{(4)}$. Genetic, lifestyle and environmental factors have been associated with MetS. For instance, circadian clock genes ${ }^{(5)}$, location (urban or rural area), low physical activity and obesity ${ }^{(6)}$ might affect MetS. The majority of studies have assessed the nutritional determinants of MetS, with the associations between dietary foods, nutrients, dietary patterns and MetS being investigated. Some food patterns such as rich potato and meat dishes can increase the risk of $\operatorname{MetS}^{(7)}$, and high 
consumption of dairy products, foods rich in grains and fish might decrease the risk of $\mathrm{MetS}^{(8)}$; however, some researchers reported that there was no association between the intake of meat or fish and risk of $\operatorname{MetS}^{(9)}$. Also, daily consumption of fruits and vegetables may have inverse effects on $\mathrm{MetS}^{(10)}$. The Mediterranean diet decreases the risk of MetS owing to large intakes of fruits and vegetables, while the Western diet increases the risk of MetS owing low intake of fruits and high intakes of red and processed meats $^{(11)}$. Also, undesirable mealtime habits can increase the risk of MetS tenfold ${ }^{(12)}$.

Dietary habits are also important factors that might affect the risk of non-communicable diseases including MetS. A limited number of studies have tried to examine food intake habits in association with $\mathrm{MetS}^{(13)}$. In a study performed in a Saudi community, most of the participants (83.9\%) removed skin from poultry and consumed moderate amounts of oil and salt (59.9\%), but the effect of these dietary habits on MetS was not assessed ${ }^{(14)}$. In Taiwan, changes in dietary habits such as consuming cake, sweets, and generally large energy intake have enhanced the risk of MetS. People in Taiwan traditionally eat the skin on poultry and high-fat meat, but these dietary habits have decreased from 50\% during 1993-1996 to 40\% in 2008. During this time, consumption of vegetables and fruits increased and use of high-fat dairy decreased. However, MetS has increased from $10 \%$ in 1993-1996 to $31.5 \%$ in $2008^{(15)}$. It was shown in a cross-sectional study in Iran that consuming whole grains can reduce the odds of MetS and its components, while refined grains could increase the odds of MetS and its components ${ }^{(16)}$. Also, intake of white rice (low-fibre food) as a staple food ${ }^{(17)}$ and higher consumption of red meats ${ }^{(18)}$ might increase the risk of MetS in the Iranian adult population. However, we did not find any studies about the effect of dietary habits on the risk of MetS. The effect of dietary habits on the risk of MetS might be different based on the population in which the study takes place ${ }^{(13)}$. To the best of our knowledge, no studies have tried to investigate such an association in the Middle East using a prospective design. The present study aimed at determining the effect of dietary habits on the risk of MetS in a 10-year follow-up study in central Iran.

\section{Materials and methods}

\section{Study population}

In the first wave of the cohort study, 1979 participants aged 20-74 years were recruited in the context of the Yazd Healthy Heart Project (YHHP) during 2005-2006 using the cluster sampling method. They were also re-invited to the Yazd Cardiovascular Research Center to be re-evaluated during 2015-2016. The participants were selected from the urban population of Yazd city. Yazd is the capital of Yazd province and is located in the central part of Iran. At baseline, the prevalence of MetS was $44 \cdot 8 \%$ ( $n$ 887).
Therefore, all participants from Yazd city aged 20-74 years at baseline (2005-2006) and without MetS ( $n$ 1092) were included in the present study. They were followed-up for 10 years and were re-assessed for MetS during 2015-2016. The participants were invited to the Yazd Cardiovascular Research Center again during 2015-2016 over the telephone by a clinical psychologist with good communication skills to prevent subject attrition as far as possible in the follow-up. After repeated measurements, 283 out of 1092 participants were lost to follow-up and finally the data of 809 participants were completed at the end of the study. The cumulative 10-year incidence of MetS was found to be $56.1 \%$ ( $n$ 454). The details on the study protocol are reported elsewhere $^{(19)}$.

\section{Ethical approval}

The study was approved by the Ethics Committee of Shahid Sadoughi University of Medical Sciences in Yazd, Iran (ethical code: IR.SSU.MEDICINE.REC.1395.287). Also, at the first and the second phases of the study, informed consents were obtained from all participants. This article is reported based on the STROBE (Strengthening the Reporting of Observational Studies in Epidemiology) Statement ${ }^{(20)}$.

\section{Data collection}

During 2005-2006, data on demographics, anthropometrics, economics, education, physical activity, smoking status and dietary habits were collected. During 2015-2016, to estimate the cumulative incidence of MetS, biochemical tests, anthropometric measurements (weight, height and waist circumference) and blood pressure assessments were repeated.

\section{Anthropometric and blood pressure measurements}

Participants' height was measured accurately without shoes with a stadiometer to the nearest $0 \cdot 1 \mathrm{~cm}$ and their weight was assessed with an Omron Karada Body Scan and Scale (model BF511; Omron Co., Osaka, Japan) to the nearest $0 \cdot 1 \mathrm{~kg}$. The upper iliac crest was selected to measure waist circumference with a tape measure. Blood pressure was assessed twice by a trained nurse using an automatic digital blood pressure monitor (model M6 Comfort; Omron Co.), with an interval of $5 \mathrm{~min}$ between readings and the participant in a seated position.

\section{Assessment of dietary babits}

Data on dietary habits were collected via a researchermade dietary habit questionnaire that was used during 2005-2006 and designed by experts in nutrition. Content validity of the dietary habits questionnaire was determined by experts in the field of nutrition. We also checked the reliability of the dietary habits questionnaire using Cronbach's alpha and it was assessed to be reasonable 
( $\alpha=0.63)$. The participants were asked about their dominant dietary habits including being on a special diet (yes/no), eating salad (yes/no), consuming mayonnaise (a high-fat creamy dressing used as condiment), following a weight-control programme (yes/no), salt intake with food when eating (yes/no), removing poultry skin before cooking or eating (yes/no), type of dairy product consumed (low/high fat), paying attention to food labels (yes/no), eating canned or fast foods or foods prepared in restaurants (yes/no), the predominant method used for cooking (boiling/frying/roasting), consumption of high-fat meat (yes/no) and using a special measuring cup for adding oil and salt when cooking (yes/no).

\section{Diagnosis of metabolic syndrome}

Five components of MetS, including abdominal obesity, hypertension and biochemical tests (fasting blood glucose, TAG and HDL-C levels), were measured. Blood was taken from a vein after $9-12 \mathrm{~h}$ of fasting. To evaluate fasting blood glucose and TAG, a biochemical auto-analyser (model BT 3000 plus; Biotechnica, Rome, Italy) and relevant kits (Pars Azmoon Inc., Tehran, Iran) were used. HDL-C was assessed using Bionic kits (Bionic Co., Tehran, Iran). In the current study, diagnosis of MetS was established using the new version of the NCEP ATP III criteria $^{(21,22)}$. MetS was defined according to a revised version of NCEP ATP III criteria adapted for Iranians. Based on this definition, the participants who had three out of five components of MetS were considered as having MetS. These components included: blood pressure $\geq 130 / 85 \mathrm{mmHg}$ or taking a treatment for hypertension; fasting blood glucose $\geq 100 \mathrm{mg} / \mathrm{dl}$ or taking drugs to treat diabetes; TAG level $\geq 150 \mathrm{mg} / \mathrm{dl}$; HDL-C $<40 \mathrm{mg} / \mathrm{dl}$ in men or $<50 \mathrm{mg} / \mathrm{dl}$ in women or treatment for dyslipidaemia; and abdominal obesity defined as waist circumference $\geq 91.5 \mathrm{~cm}$ for men or $\geq 85.5 \mathrm{~cm}$ for women ${ }^{(23)}$.

\section{Economic status}

At the first phase of the study during 2005-2006, based on the oral responses to a questionnaire by the participants, economic status was considered based on scoring three variables, including home area (square metres), household income and having a private car. According to tertiles of summed score of these three variables (economic score), the participants were classified into low, moderate and high economic status groups.

\section{Physical activity}

Level of physical activity was assessed by the International Physical Activity Questionnaire (IPAQ) ${ }^{(24)}$. Based on the cut-off points of physical activity level of 2510 and $5020 \mathrm{~kJ} /$ week (600 and $1200 \mathrm{kcal} /$ week), the participants were divided into three groups of low $(<2510 \mathrm{~kJ} /$ week (<600 kcal/week)), moderate (2510-5020 kJ/week
$(600-1200 \mathrm{kcal} /$ week)) and vigorous (>5020 kJ/week (>1200 kcal/week)).

\section{Assessment of other covariates}

Education was classified into three categories according to the level of education (primary school, high school diploma, academic degree). Furthermore, the participants were asked about their smoking habits and then they were divided into two categories (smokers, non-smokers).

\section{Statistical analysis}

Data were analysed using the statistical software package IBM SPSS Statistics version 19. To compare the means of quantitative variables such as age, weight, BMI and components of MetS (waist circumference, high fasting blood glucose, systolic blood pressure, diastolic blood pressure, TAG and HDL-C levels) between the two groups of MetS developers and healthy participants, the independent Student $t$ test was used. To find any significant differences in categorical variables such as sex, smoking, economic status, physical activity and educational level between the two groups (MetS and non-MetS), the $\chi^{2}$ test was used. Cox proportional hazards regression analyses were used to find the associations between dietary habits and MetS risk in crude and adjusted models in men and women, separately. In model I, the association was adjusted for age and sex; in model II, smoking, economic status, physical activity and educational level were additionally adjusted. $P$ values less than 0.05 were considered statistically significant.

\section{Results}

The mean age of the participants who had MetS was $45 \cdot 1$ (SD 13.3) years; also, $53.5 \%$ ( $n$ 243) of those with MetS were male while $46.5 \%$ ( $n$ 211) of them were female. A comparison of characteristics between the participants with and without MetS is shown in Table 1. We found statistically significant differences in age and weight, BMI, systolic blood pressure, diastolic blood pressure, fasting blood glucose, TAG, HDL-C, waist circumference and educational level between the two groups. Participants in the MetS group were significantly older, had higher body weight and waist circumference, higher systolic and diastolic blood pressures, and higher levels of fasting blood glucose and serum TAG than the healthy group $(P=0 \cdot 001)$. There were no significant differences in sex, smoking, economic status and physical activity between the two groups.

The risk of MetS related to dietary habits in the total population at the 10-year follow-up is demonstrated in Table 2. In model I, after adjustment for sex and age, participants who did not use a special measuring cup for adding oil (hazard ratio $(\mathrm{HR})=1 \cdot 22 ; 95 \%$ CI $1.00,1.49$ ) 
Table 1 Baseline characteristics of the study population and comparison between participants who did and did not develop metabolic syndrome (MetS) over the 10-year follow-up; Yazd Healthy Heart Project, Iran

\begin{tabular}{|c|c|c|c|c|c|c|c|}
\hline \multirow[b]{2}{*}{ Variable } & \multicolumn{2}{|c|}{ Total $(n 809)$} & \multicolumn{2}{|c|}{$\begin{array}{l}\text { MetS developers (cases) } \\
(\text { ( } 454)\end{array}$} & \multicolumn{2}{|c|}{$\begin{array}{l}\text { Non-MetS developers } \\
(n \text { 355) }\end{array}$} & \multirow[b]{2}{*}{$P$ value } \\
\hline & Mean & SD & Mean & SD & Mean & SD & \\
\hline Age (years) & 43.0 & $14 \cdot 4$ & $45 \cdot 1$ & $13 \cdot 3$ & $40 \cdot 3$ & $15 \cdot 4$ & 0.001 \\
\hline Weight $(\mathrm{kg})$ & 68.6 & $12 \cdot 2$ & $70 \cdot 7$ & 12.0 & $65 \cdot 8$ & 11.9 & 0.001 \\
\hline $\operatorname{BMI}\left(\mathrm{kg} / \mathrm{m}^{2}\right)$ & 24.9 & $4 \cdot 1$ & $25 \cdot 7$ & 3.7 & 23.9 & $4 \cdot 3$ & 0.001 \\
\hline Systolic blood pressure $(\mathrm{mmHg})$ & 121.9 & $12 \cdot 7$ & $123 \cdot 7$ & $13 \cdot 0$ & $119 \cdot 5$ & $12 \cdot 0$ & 0.001 \\
\hline Diastolic blood pressure $(\mathrm{mmHg})$ & $79 \cdot 8$ & 7.5 & $80 \cdot 7$ & $7 \cdot 3$ & 78.6 & $7 \cdot 6$ & 0.001 \\
\hline Fasting glucose $(\mathrm{mg} / \mathrm{dl})$ & $87 \cdot 2$ & $23 \cdot 1$ & 90.5 & $28 \cdot 3$ & $83 \cdot 0$ & $12 \cdot 8$ & 0.001 \\
\hline TAG $(\mathrm{mg} / \mathrm{dl})$ & $129 \cdot 2$ & 69.7 & 143.9 & $74 \cdot 4$ & $110 \cdot 3$ & $58 \cdot 0$ & 0.001 \\
\hline HDL cholesterol (mg/dl) & $56 \cdot 8$ & $13 \cdot 3$ & $56 \cdot 0$ & $12 \cdot 7$ & 57.9 & $13 \cdot 8$ & 0.04 \\
\hline \multirow[t]{2}{*}{ Waist circumference $(\mathrm{cm})$} & 88.7 & $11 \cdot 2$ & $91 \cdot 1$ & $10 \cdot 2$ & $85 \cdot 6$ & $11 \cdot 7$ & 0.001 \\
\hline & $n$ & $\%$ & $n$ & $\%$ & $n$ & $\%$ & \\
\hline \multicolumn{8}{|l|}{ Sex } \\
\hline Male & 441 & 54.5 & 243 & 53.5 & 198 & $55 \cdot 8$ & 0.52 \\
\hline Female & 368 & 45.5 & 211 & $46 \cdot 5$ & 157 & $44 \cdot 2$ & \\
\hline \multicolumn{8}{|l|}{ Smoking status } \\
\hline Smokers & 140 & $17 \cdot 3$ & 69 & $15 \cdot 2$ & 71 & $20 \cdot 0$ & 0.07 \\
\hline Non-smokers & 669 & $82 \cdot 7$ & 385 & 84.8 & 284 & $80 \cdot 0$ & \\
\hline \multicolumn{8}{|l|}{ Economic status } \\
\hline Low & 94 & $25 \cdot 2$ & 51 & $24 \cdot 3$ & 43 & $26 \cdot 4$ & 0.14 \\
\hline Moderate & 149 & 39.9 & 77 & $36 \cdot 7$ & 72 & 44.2 & \\
\hline High & 130 & 34.9 & 82 & 39.0 & 48 & $29 \cdot 4$ & \\
\hline \multicolumn{8}{|l|}{ Physical activity } \\
\hline Low & 326 & 60.5 & 183 & $61 \cdot 6$ & 143 & $59 \cdot 1$ & 0.84 \\
\hline Moderate & 181 & 33.6 & 97 & $32 \cdot 7$ & 84 & 34.7 & \\
\hline Vigorous & 32 & 5.9 & 17 & 5.7 & 15 & $6 \cdot 2$ & \\
\hline \multicolumn{8}{|l|}{ Educational level } \\
\hline Low & 363 & $46 \cdot 7$ & 226 & $50 \cdot 8$ & 137 & $41 \cdot 1$ & 0.02 \\
\hline Moderate & 313 & $40 \cdot 2$ & 168 & 37.8 & 145 & 43.5 & \\
\hline High & 102 & 13.1 & 51 & 11.5 & 51 & $15 \cdot 3$ & \\
\hline
\end{tabular}

Table 2 Hazard ratio $(\mathrm{HR})$ and $95 \% \mathrm{Cl}$ for development of metabolic syndrome based on dietary habits in the total population of the Yazd Healthy Heart Project, Iran

\begin{tabular}{|c|c|c|c|c|c|c|}
\hline \multirow[b]{2}{*}{ Risk factor } & \multicolumn{2}{|c|}{ Crude } & \multicolumn{2}{|c|}{ Adjusted (model I)* } & \multicolumn{2}{|c|}{ Adjusted (model II)† } \\
\hline & $\mathrm{HR}$ & $95 \% \mathrm{Cl}$ & $\mathrm{HR}$ & $95 \% \mathrm{Cl}$ & $\mathrm{HR}$ & $95 \% \mathrm{Cl}$ \\
\hline Weight-control programme (no) & 1.18 & $0.97,1.44$ & 1.07 & $0 \cdot 87,1 \cdot 31$ & 1.57 & $1.06,2.35$ \\
\hline Being on a special diet (no) & 0.76 & $0.62,0.93$ & 0.83 & $0.67,1.02$ & 0.59 & $0.40,0.86$ \\
\hline Eating salad (no) & 1.25 & $1.01,1.56$ & 1.17 & $0.94,1.46$ & 1.91 & $1.22,3.00$ \\
\hline Consuming mayonnaise (yes) & 0.88 & $0.71,1.09$ & 0.96 & $0.77,1.20$ & 0.88 & $0.58,1.34$ \\
\hline Salt intake with food when eating (yes) & 1.05 & $0.87,1.28$ & 1.21 & $0.98,1.49$ & 1.57 & $1.06,2.33$ \\
\hline Remove poultry skin (no) & 0.82 & $0.58,1.15$ & 0.83 & $0.59,1.19$ & 0.66 & $0.38,1.14$ \\
\hline High-fat dairy (yes) & 1.08 & $0.88,1.34$ & 1.07 & $0.87,1.34$ & 0.80 & $0.54,1.19$ \\
\hline Attention to food labels (no) & 0.99 & $0.82,1.19$ & 0.90 & $0.73,1.08$ & 0.93 & $0.64,1.38$ \\
\hline Eating food out of home (yes) & 0.97 & $0.80,1.19$ & 1.11 & $0.90,1.37$ & 1.09 & $0.75,1.59$ \\
\hline Canned food (yes) & 1.08 & $0.63,1.86$ & 1.13 & $0.66,1.94$ & 1.41 & $0.34,5.86$ \\
\hline Fast food (yes) & 0.80 & $0.62,1.02$ & 0.98 & $0.74,1.30$ & $1 \cdot 30$ & $0.76,2 \cdot 22$ \\
\hline Foods prepared in restaurant (yes) & 0.53 & $0.37,0.87$ & 0.59 & $0.40,0.89$ & 0.39 & $0.21,0.76$ \\
\hline Fried food (yes) & 0.74 & $0.60,0.90$ & 0.80 & $0.66,0.99$ & 0.86 & $0.58,1.28$ \\
\hline Roasted food (yes) & 0.86 & $0.46,1.61$ & 0.98 & $0.52,1.84$ & 0.74 & $0.23,2.38$ \\
\hline Boiled food (no) & 0.74 & $0.61,0.90$ & 0.82 & $0.67,1.00$ & 0.84 & $0.57,1.24$ \\
\hline High-fat meat (yes) & 1.09 & $0.88,1.36$ & 1.14 & $0.91,1.42$ & 0.98 & $0.63,1.53$ \\
\hline Special measuring cup for adding oil (no) & 1.15 & $0.94,1.40$ & 1.22 & $1.00,1.49$ & $1 \cdot 10$ & $0.72,1.70$ \\
\hline Special measuring cup for adding salt (no) & 1.23 & $0.99,1.50$ & 1.27 & $1.03,1.56$ & 1.30 & $0.84,2.05$ \\
\hline
\end{tabular}

*Model I: adjusted for age and sex.

†Model II: adjusted for age, sex, smoking, economic status, physical activity and education.

and participants who did not use a special measuring cup for adding salt ( $\mathrm{HR}=1.27 ; 95 \%$ CI $1.03,1.56)$ had a higher risk for MetS than the rest of the participants.
In model II, after further adjustment for smoking, economic status, physical activity and educational level, the risk of MetS in participants who had no weight-control programme $(\mathrm{HR}=1 \cdot 57 ; 95 \%$ CI $1 \cdot 06,2 \cdot 35)$, did not usually 
Table 3 Hazard ratio $(\mathrm{HR})$ and $95 \% \mathrm{Cl}$ for development of metabolic syndrome based on dietary habits in men and women of the Yazd Healthy Heart Project, Iran

\begin{tabular}{|c|c|c|c|c|c|c|c|c|c|c|c|c|}
\hline \multirow[b]{3}{*}{ Risk factor } & \multicolumn{6}{|c|}{ Men } & \multicolumn{6}{|c|}{ Women } \\
\hline & \multicolumn{2}{|r|}{ Crude } & \multicolumn{2}{|c|}{$\begin{array}{l}\text { Adjusted } \\
\text { (model I)* }^{*}\end{array}$} & \multicolumn{2}{|c|}{$\begin{array}{l}\text { Adjusted } \\
\text { (model II)† }\end{array}$} & \multicolumn{2}{|r|}{ Crude } & \multicolumn{2}{|c|}{$\begin{array}{l}\text { Adjusted } \\
\text { (model I) }^{*}\end{array}$} & \multicolumn{2}{|c|}{$\begin{array}{l}\text { Adjusted } \\
\text { (model II) } \dagger\end{array}$} \\
\hline & $\mathrm{HR}$ & $95 \% \mathrm{Cl}$ & $\mathrm{HR}$ & $95 \% \mathrm{Cl}$ & HR & $95 \% \mathrm{Cl}$ & $\mathrm{HR}$ & $95 \% \mathrm{Cl}$ & $\mathrm{HR}$ & $95 \% \mathrm{Cl}$ & $\mathrm{HR}$ & $95 \% \mathrm{Cl}$ \\
\hline Weight-control programme (no) & 1.26 & $0.95,1.66$ & 1.17 & $0.88,1.56$ & 1.72 & $1.08,2.74$ & $1 \cdot 10$ & $0.83,1.44$ & 0.97 & $0.72,1.30$ & 1.22 & $0.55,2.68$ \\
\hline Being on a special diet (no) & 0.78 & $0.58,1.04$ & 0.87 & $0.65,1.18$ & 0.65 & $0.41,1.03$ & 0.76 & $0.57,1.02$ & 0.82 & $0.61,1.10$ & 0.45 & $0.23,0.89$ \\
\hline Eating salad (no) & 1.60 & $1 \cdot 20,2 \cdot 16$ & 1.49 & $1 \cdot 10,2 \cdot 02$ & $2 \cdot 41$ & $1.43,4.08$ & 0.98 & $0.70,1.35$ & 0.93 & $0.67,1.29$ & 0.89 & $0.32,2.50$ \\
\hline Consuming mayonnaise (yes) & 0.90 & $0.66,1.20$ & 1.00 & $0.73,1.36$ & 0.89 & $0.54,1.45$ & 0.89 & $0.65,1.21$ & 0.95 & $0.69,1.31$ & 0.87 & $0.36,2.11$ \\
\hline $\begin{array}{l}\text { Salt intake with food when eating } \\
\text { (yes) }\end{array}$ & 1.00 & $0.76,1.30$ & $1 \cdot 13$ & $0.85,1.49$ & 1.40 & $0.89,2 \cdot 23$ & 1.17 & $0.87,1.58$ & 1.34 & $0.98,1.83$ & $2 \cdot 16$ & $0.97,4.84$ \\
\hline Remove poultry skin (no) & 0.71 & $0.45,1.11$ & 0.71 & $0.45,1.10$ & 0.63 & $0.33,1.22$ & 1.03 & $0.60,1.77$ & $1 \cdot 10$ & $0.63,1.88$ & 0.79 & $0.29,2.14$ \\
\hline High-fat dairy (yes) & $1 \cdot 10$ & $0.84,1.46$ & $1 \cdot 10$ & $0.83,1.44$ & 0.74 & $0.48,1.16$ & $1 \cdot 10$ & $0.75,1.50$ & $1 \cdot 10$ & $0.75,1.50$ & 1.27 & $0.53,3.02$ \\
\hline Eating food out of home (yes) & 1.07 & $0.80,1.43$ & 1.22 & $0.90,1.65$ & $1 \cdot 21$ & $0.76,1.92$ & 0.88 & $0.67,1.17$ & 1.00 & $0.75,1.35$ & 0.86 & $0.41,1.76$ \\
\hline Canned food (yes) & $1 \cdot 15$ & $0.56,2.34$ & $1 \cdot 10$ & $0.52,2 \cdot 18$ & $2 \cdot 37$ & $0.32,17.69$ & 1.00 & $0.44,2.29$ & 1.39 & $0.59,3.27$ & 0.66 & $0.04,9.36$ \\
\hline Fast food (yes) & 1.03 & $0.75,1.43$ & 1.40 & $0.95,2 \cdot 10$ & 1.62 & $0.88,2.98$ & 0.55 & $0.37,0.82$ & 0.64 & $0.42,0.98$ & 0.66 & $0.18,2 \cdot 32$ \\
\hline $\begin{array}{l}\text { Foods prepared in restaurant } \\
\text { (yes) }\end{array}$ & 0.59 & $0.38,0.92$ & 0.66 & $0.42,1.04$ & 0.55 & $0.27,1 \cdot 10$ & 0.40 & $0.17,0.92$ & 0.43 & $0.19,0.99$ & 0.08 & $0.01,0.82$ \\
\hline Fried food (yes) & 0.75 & $0.58,0.98$ & 0.83 & $0.64,1.09$ & 0.74 & 0.47 & 0.69 & $0.51,0.93$ & 0.76 & 0.56 & 1.24 & $0.59,2.63$ \\
\hline Boiled food (no) & 0.78 & $0.60,1.01$ & 0.86 & $0.65,1.12$ & 0.74 & $0.47,1.18$ & 0.69 & $0.51,0.93$ & 0.77 & $0.56,1.05$ & 1.26 & $0.59,2.67$ \\
\hline High-fat meat (yes) & 0.99 & $0.73,1.35$ & 1.06 & $0.78,1.45$ & $1 \cdot 13$ & $0.68,1 \cdot 87$ & 1.22 & $0.88,1.67$ & 1.24 & $0.90,1.70$ & 0.62 & $0.22,1.74$ \\
\hline $\begin{array}{l}\text { Using special measuring cup for } \\
\text { adding oil (no) }\end{array}$ & $1 \cdot 12$ & $0.85,1.47$ & $1 \cdot 23$ & $0.93,1.62$ & 1.41 & $0 \cdot 86,2 \cdot 33$ & $1 \cdot 18$ & $0.89,1.57$ & $1 \cdot 22$ & $0.90,1.62$ & 0.60 & $0.20,1.50$ \\
\hline $\begin{array}{l}\text { Using special measuring cup for } \\
\text { adding salt (no) }\end{array}$ & 1.25 & $0.94,1.65$ & 1.33 & $1.00,1 \cdot 76$ & 1.61 & $0 \cdot 96,2 \cdot 70$ & 1.20 & $0.88,1.62$ & $1 \cdot 21$ & $0.89,1.64$ & 0.77 & $0.27,2 \cdot 13$ \\
\hline
\end{tabular}

${ }^{*}$ Model I: adjusted for age.

†Model II: adjusted for age, smoking, economic status, physical activity and education.

eat salad (HR $=1.91 ; 95 \%$ CI $1 \cdot 22,3.00)$ and consumed salt with food $(\mathrm{HR}=1 \cdot 57$; $95 \%$ CI $1 \cdot 06,2 \cdot 33)$ was higher than in the other participants; however, the risk of MetS in participants who were not on a special diet (non-diabetic and non-hypertensive diet) was significantly lower compared with those with a special diet $(\mathrm{HR}=0.59 ; 95 \% \mathrm{CI}$ 0.40, 0.86). Participants who consumed fried foods had lower risk for MetS after adjustment for sex and age ( $\mathrm{HR}=0.80 ; 95 \%$ CI 0.66, 0.99), but there was no association between consuming fried foods and MetS after adjustment for all potential confounders in model II.

The results in Table 3 show the risk for MetS in association with dietary habits according to sex. In men, after adjustment for covariates (model II), the risk of MetS in those who had no weight-control programme $(\mathrm{HR}=1.72$; $95 \%$ CI $1.08,2 \cdot 74)$ and who did not eat salad $(\mathrm{HR}=2.41$; $95 \%$ CI $1.43,4.08)$ was higher than in their counterparts who had these behaviours. The risk of MetS in women who were not on a special diet was significantly lower than in those with a special diet $(\mathrm{HR}=0.45 ; 95 \%$ CI 0.23 , 0.89). No other significant associations were found between dietary habits and risk of MetS in women.

\section{Discussion}

In the current cohort study, after a 10-year follow-up in an Iranian population, some associations were found between dietary habits and increased risk of MetS. First, after adjustment for potential confounders in model II, the risk of MetS was increased in the participants who did not have a programme for controlling their body weight. Similar to our results, another study emphasized that obesity is the result of a lack of body weight control, low physical activity and, especially, dietary habits with high energy intake ${ }^{(25)}$. The results of the current study showed that the risk of MetS increased in those who did not eat salad. It is interesting that when data were stratified by sex, such an association was significant in men whereas there was no significantly increased risk of MetS according to eating salad in women. Other studies have reported that consumption of vegetables can decrease the risk of MetS $S^{(10,26,27)}$. However, consumption of vegetables could decrease inflammatory markers, cardiovascular events and diabetes via their constituents such as antioxidants and consequently lead to a decreased risk of $\operatorname{MetS}^{(10,28)}$. Although no significant association was found between eating salad and risk of MetS in women in the present study, another study conducted in Tehran, Iran, revealed that consumption of vegetables decreases the risk of MetS by $30 \%$ compared with the lowest quintile ${ }^{(10)}$. This inconsistency of results among the studies may be attributed to factors such as use of the modified version of the NCEP ATP III criteria instead of the original NCEP ATP III criteria and the use of BMI instead of high fasting blood glucose to define MetS, as well as to the long-term rather than short-term consumption of vegetables. It should be noted that the definition of MetS in our study was 
consistent over time in both phases of the study. Also, other components of MetS such as dyslipidaemia and high blood pressure might change diet and subsequently would serve as confounders in the correlation between vegetable intake and $\mathrm{MetS}^{(10)}$

In the present study, the risk of MetS decreased based on high-fat dairy consumption (in model II) rather than low-fat dairy in the total population, but the difference was not statistically significant. Also, a cohort study conducted in Brazil showed no association between low-fat dairy intake and MetS risk, even though the consumption of full-fat dairy could decrease the risk of MetS for every additional daily intake $^{(29)}$. In a meta-analysis of seven cohort studies, relative risk of MetS decreased with higher consumption of dairy foods (relative risk $=0.86 ; 95 \%$ CI $0.8,0 \cdot 9)^{(30)}$. These results were similar for the Iranian population in the Tehran Lipid and Glucose Study ${ }^{(31)}$. The SFA in milk can affect metabolism of foods and lead to reduced hypertriacylglycerolaemia and hypercholesterolaemia. Furthermore, milk fat is proposed to elevate HDL-C ${ }^{(32)}$.

In the current study, there was no association between high-fat meat and MetS. Although the other researchers reported that a high intake of dietary fat can lead to insulin resistance and $\mathrm{MetS}^{(33)}$, it depends on the type of fat and its degree of saturation ${ }^{(34)}$.

In our study (in model II), a statistically significant increased risk of MetS was observed for salt intake with food in the total population. A similar result was seen among participants who had no measuring cup for adding salt in model $\mathrm{I}$ in the total population and after stratifying by sex in men. Similar to our results, other studies emphasize that high consumption of salt is associated with an increase in the risk of MetS ${ }^{(35,36)}$ and reported that there was a significant difference in the associations between high salt intake and all components of MetS ${ }^{(36)}$. However, lipogenic enzymes can be increasingly active in participants who have high-salt dietary habits and the process of synthesis of glucose into lipids will be developed ${ }^{(37)}$. Also, a high-salt diet can increase lipid metabolism and insulin resistance and, as a result of increased energy intake, waist circumference and BMI can be increased ${ }^{(36)}$.

In the current study, after adjustment for all potential cofounders, no significant differences were seen between consumption of poultry with or without skin, high-fat meat and fried, roasted and boiled food consumption and the risk of MetS. However, some researchers have reported that high-fat food and fried food intake can increase the risk of $\mathrm{MetS}^{(34)}$.

In the present study, the risk of MetS in participants who were not on a special diet was significantly lower compared with those with a special diet. This may be attributed to the risk factors pertaining to the participants who went on a diet compared with other subjects without any special diet. Also, another reason may be changes in the risk factors that affect the components of MetS in the participants during the 10 years of the study ${ }^{(38)}$.
The present study was the first cohort study on the effect of dietary habits on the risk of MetS in an Iranian population and the Middle East. There are some limitations in the study that might affect the final results. First, $26 \%$ of the participants in our study who did not have MetS at baseline during 2005-2006 were lost to follow-up at the second phase during 2015-2016. Although this limitation was unavoidable, an attempt was made to decrease the attrition in any way possible. Second, we lost the exact time of occurrence of MetS, because repeated measurements were performed about 10 years after the start of the study. It would have been better if repeated measurements were performed each year. Third, in the questionnaire used in our study, most of the dietary habits items were answered as yes/no. Fourth, we could not check the participants during the follow-up period. Therefore, their lifestyle including physical activity, dietary habits, smoking, etc. might have changed. The change in the independent variables might reduce the power of the study to find the true risk estimates. Nevertheless, we can be confident that the associations found in the present study might be even more predictive in this population. Finally, it should be noted that the present study was conducted in a small area of Iran; therefore, its results should be considered with caution when generalizing to other populations.

\section{Conclusion}

In the present study, dietary habits like the lack of a weight-control programme, lack of salad eating and high salt consumption increased the risk of MetS in the total population. Also, after stratifying by sex, lack of a weightcontrol programme and lack of salad eating increased the risk of MetS in men, but not in women. Therefore, dietary habit changes are recommended. More studies are needed to find out the precise role of dietary habits in increasing the risk of MetS.

\section{Acknowledgements}

Acknowledgements: The authors thank all colleagues in the Yazd Cardiovascular Research Center for their cooperation in performing this research; special thanks go to Dr Hadiani, Dr Jalilian and Mrs Lesan and all staff in Afshar Hospital Laboratory in Yazd, Iran. Financial support: This project was supported by Shahid Sadoughi University of Medical Sciences in Yazd, Iran and the Iran National Science Foundation (INSF); the study was not supported by industry. The funders had no role in the design, analysis or writing of this article. Conflict of interest: There were no financial conflicts of interest during follow-up, analysis of data and reporting results of the study. Authorship: Study concept and design: S.J.M., M.S., S.M.N., M.M., M.H.S., 
A.P. and A.S.-A. Sampling: M.S., Z.B. and R.F. Statistical analysis: A.S.-A. and M.S. Drafting of the manuscript: M.S. Critical revision of the manuscript for important intellectual content: M.S., M.M., S.M.N., A.S.-A. and M.P. Ethics of buman subject participation: The Ethics Committee of Shahid Sadoughi University of Medical Sciences in Yazd, Iran (ethical code: IR.SSU.MEDICINE.REC.1395.287) approved the study and all participants provided informed consent.

\section{References}

1. Li Z, Yang X, Yang J et al. (2016) The cohort study on prediction of incidence of all-cause mortality by metabolic syndrome. PLoS One 11, e0154990.

2. Ervin RB (2009) Prevalence of metabolic syndrome among adults 20 years of age and over, by sex, age, race and ethnicity, and body mass index: United States, 2003-2006. Natl Health Stat Report issue 13, 1-7.

3. Sadrbafoghi SM, Salari M, Rafiee M et al. (2006) Prevalence and criteria of metabolic syndrome in an urban population: Yazd Healthy Heart Project. Tehran Univ Med J 64, 90-96.

4. Jiang B, Li B, Wang Y et al. (2016) The nine-year changes of the incidence and characteristics of metabolic syndrome in China: longitudinal comparisons of the two cross-sectional surveys in a newly formed urban community. Cardiovasc Diabetol 15, 84 .

5. Lin E, Kuo PH, Liu YL et al. (2017) Effects of circadian clock genes and health-related behavior on metabolic syndrome in a Taiwanese population: evidence from association and interaction analysis. PLoS One 12, e0173861.

6. Hwang JH, Kam S, Shin JY et al. (2013) Incidence of metabolic syndrome and relative importance of five components as a predictor of metabolic syndrome: 5-year follow-up study in Korea. J Korean Med Sci 28, 1768-1773.

7. Panagiotakos DB, Pitsavos C, Skoumas Y et al. (2007) The association between food patterns and the metabolic syndrome using principal components analysis: the ATTICA Study. J Am Diet Assoc 107, 979-987.

8. Ruidavets JB, Bongard V, Dallongeville J et al. (2007) High consumptions of grain, fish, dairy products and combinations of these are associated with a low prevalence of metabolic syndrome. J Epidemiol Community Health 61, 810-817.

9. Lutsey PL, Steffen LM \& Stevens J (2008) Dietary intake and the development of the metabolic syndrome: the Atherosclerosis Risk in Communities Study. Circulation 117, 754-761.

10. Esmaillzadeh A, Kimiagar M, Mehrabi Y et al. (2006) Fruit and vegetable intakes, C-reactive protein, and the metabolic syndrome. Am J Clin Nutr 84, 1489-1497.

11. de Oliveira E, Manda R, Torezan G et al. (2011) Dietary, anthropometric, and biochemical determinants of plasma high-density lipoprotein-cholesterol in free-living adults. Cholesterol 2011, 851750.

12. Mendez-Hernandez P, Dosamantes-Carrasco LD, Siani C et al. (2016) Mealtime habits and risk of developing the metabolic syndrome or insulin resistance among Mexican adults. Br J Nutr. Published online: 15 November 2016. doi: 10.1017/S0007114516003329.

13. Shin A, Lim S-Y, Sung J et al. (2009) Dietary intake, eating habits, and metabolic syndrome in Korean men. J Am Diet Assoc 109, 633-640.

14. Al-Khateeb BF \& Al-Gelban KS (2008) Dietary habits in a suburban Saudi community. Biomed Res 19, 55-59.
15. Pan W-H, Wu H-J, Yeh C-J et al. (2011) Diet and health trends in Taiwan: comparison of two nutrition and health surveys from 1993-1996 and 2005-2008. Asia Pac J Clin Nutr 20, 238-250.

16. Esmaillzadeh A, Mirmiran P \& Azizi F (2005) Whole-grain consumption and the metabolic syndrome: a favorable association in Tehranian adults. Eur J Clin Nutr 59, 353-362.

17. Bahadoran Z, Mirmiran P, Delshad H et al. (2014) White rice consumption is a risk factor for metabolic syndrome in Tehrani adults: a prospective approach in Tehran Lipid and Glucose Study. Arch Iran Med 17, 435-440.

18. Azadbakht L \& Esmaillzadeh A (2009) Red meat intake is associated with metabolic syndrome and the plasma C-reactive protein concentration in women. J Nutr 139, 335-339.

19. Sarebanhassanabadi M, Jalil Mirhosseini S, Mirzaei M et al. (2017) The incidence of metabolic syndrome and the most powerful components as predictors of metabolic syndrome in central Iran: a 10-year follow-up in a Cohort Study. Iran Red Crescent Med J 19, e14934.

20. Poorolajal J, Cheraghi Z, Irani AD et al. (2011) Quality of cohort studies reporting post the Strengthening the Reporting of Observational Studies in Epidemiology (STROBE) statement. Epidemiol Health 33, e2011005.

21. Huang PL (2009) A comprehensive definition for metabolic syndrome. Dis Model Mech 2, 231-237.

22. Li Y, Yatsuya H, Iso $\mathrm{H}$ et al. (2010) Incidence of metabolic syndrome according to combinations of lifestyle factors among middle-aged Japanese male workers. Prev Med 51, 118-122.

23. Esteghamati A, Ashraf H, Rashidi A et al. (2008) Waist circumference cut-off points for the diagnosis of metabolic syndrome in Iranian adults. Diabetes Res Clin Pract 82, 104-107.

24. Maddison R, Ni Mhurchu C, Jiang Y et al. (2007) International Physical Activity Questionnaire (IPAQ) and New Zealand Physical Activity Questionnaire (NZPAQ): a doubly labelled water validation. Int J Behav Nutr Phys Act 4, 62.

25. Grundy SM, Cleeman JI, Daniels SR et al. (2005) Diagnosis and management of the metabolic syndrome. Circulation 112, 2735-2752.

26. Ford ES, Mokdad AH, Giles WH et al. (2003) The metabolic syndrome and antioxidant concentrations: findings from the Third National Health and Nutrition Examination Survey. Diabetes 52, 2346-2352.

27. Yoo S, Nicklas T, Baranowski T et al. (2004) Comparison of dietary intakes associated with metabolic syndrome risk factors in young adults: the Bogalusa Heart Study. Am J Clin Nutr 80, 841-848.

28. Wannamethee SG, Lowe GD, Rumley A et al. (2006) Associations of vitamin C status, fruit and vegetable intakes, and markers of inflammation and hemostasis. Am J Clin Nutr 83, 567-574.

29. Drehmer M, Pereira MA, Schmidt MI et al. (2015) Total and full-fat, but not low-fat, dairy product intakes are inversely associated with metabolic syndrome in adults. J Nutr 101, $775-782$.

30. Chen G-C, Szeto IMY, Chen L-H et al. (2015) Dairy products consumption and metabolic syndrome in adults: systematic review and meta-analysis of observational studies. Sci Rep 5, 14606.

31. Azadbakht L, Mirmiran P, Esmaillzadeh A et al. (2005) Dairy consumption is inversely associated with the prevalence of the metabolic syndrome in Tehranian adults. Am J Clin Nutr 82, 523-530.

32. Rice BH, Cifelli CJ, Pikosky MA et al. (2011) Dairy components and risk factors for cardiometabolic syndrome: recent evidence and opportunities for future research. Adv Nutr 2, 396-407. 
33. Grundy SM, Abate N \& Chandalia M (2002) Diet composition and the metabolic syndrome: what is the optimal fat intake? Am J Med 113, Suppl. 9B, 25S-29S.

34. Freire RD, Cardoso MA, Gimeno SGA et al. (2005) Dietary fat is associated with metabolic syndrome in Japanese Brazilians. Diabetes Care 28, 1779-1785.

35. Baudrand R, Campino C, Carvajal CA et al. (2014) High sodium intake is associated with increased glucocorticoid production, insulin resistance and metabolic syndrome. Clin Endocrinol (Oxf) 80, 677-684.
36. Oh SW, Han KH, Han SY et al. (2015) Association of sodium excretion with metabolic syndrome, insulin resistance, and body Fat. Medicine 94, e1650.

37. Fonseca-Alaniz MH, Brito LC, Borges-Silva CN et al. (2007) High dietary sodium intake increases white adipose tissue mass and plasma leptin in rats. Obesity (Silver Spring) 15, 2200-2208.

38. Chang HC, Horng JT, Chau TT et al. (2012) Relationship between changes in components associated with metabolic syndrome and disappearance, or remission, of metabolic syndrome during 1 year. $J$ Int Med Res 40, 2311-2320. 